\title{
Multi-sector thermo-physiological head simulator for headgear research
}

\author{
Natividad Martinez ${ }^{1,2} \cdot$ Agnes Psikuta $^{1} \cdot$ José Miguel Corberán $^{2} \cdot$ René M. Rossi $^{1}$ • \\ Simon Annaheim ${ }^{1}$
}

Received: 8 January 2016 /Revised: 1 June 2016 / Accepted: 5 July 2016 / Published online: 9 September 2016

(C) ISB 2016

\begin{abstract}
A novel thermo-physiological human head simulator for headgear testing was developed by coupling a thermal head manikin with a thermo-physiological model. As the heat flux at head-site is directly measured by the head manikin, this method provides a realistic quantification of the heat transfer phenomena occurring in the headgear, such as moisture absorption-desorption cycles, condensation, or moisture migration across clothing layers. Before coupling, the opportunities of the head manikin for representing the human physiology were evaluated separately. The evaluation revealed reduced precision in forehead and face temperature predictions under extreme heterogeneous temperature distributions and no initial limitation for simulating temperature changes observed in the human physiology. The thermo-physiological model predicted higher sweat rates when applied for coupled than for pure virtual simulations. After coupling, the thermophysiological human head simulator was validated using eight human experiments. It precisely predicted core, mean skin, and forehead temperatures with average rmsd values within the average experimental standard deviation (rmsd of $0.20 \pm$ $0.15,0.83 \pm 0.34$, and $1.04 \pm 0.54{ }^{\circ} \mathrm{C}$, respectively). How ever, in case of forehead, precision was lower for the exposures including activity than for the sedentary exposures. The representation of the human sweat evaporation could be affected by a reduced evaporation efficiency and the manikin sweat dynamics. The industry will benefit from this thermo-
\end{abstract}

Agnes Psikuta

agnes.psikuta@empa.ch

1 Empa, Swiss Federal Laboratories for Materials Science and Technology, St. Gallen, Switzerland

2 Department of Applied Thermodynamics, Polytechnic University of Valencia, Valencia, Spain physiological human head simulator leading to the develop ment of helmet designs with enhanced thermal comfort and, therefore, with higher acceptance by users.

\section{Introduction}

Thermal manikins are mainly designed for the examination of the heat and mass transfer in protective clothing and equipment. In most scenarios, the net heat loss as a result of convection, conduction, radiation, and eventually evaporation can be investigated using a standard operating procedure which is mainly based on the temperature-controlled regulation. Therefore, the surface temperature of a thermal manikin is typically regulated within a narrow range at a fixed set point temperature, similar to human skin temperature at a thermo neutral state, lying between 34 and $36^{\circ} \mathrm{C}$. The power needed to maintain this temperature over a steady-state period is recorded and allows the quantification of net heat loss. In the case of measuring the evaporative heat loss through garments, standard measurements usually require a fully wetted manikin surface during the entire test period. Pre-wetting the fabric is also suggested by externally water spraying the surface (ASTM F2370-10 2010).

Net heat loss has been investigated either with heated cylinders (sweating Torso, (Psikuta et al. 2008)) or anatomical full-body manikins. As an alternative, specialized body part manikins are an increasing trend. Besides the lower cost, the operation control is less complex for separate body parts, as less thermal interactions occur with the rest of the body (e.g., internal convection). In most cases, the specialized body part manikins provide a finer segmentation, allowing greater detail in the investigation of local thermal properties of garments full-body and body part manikins enable a reproducible comparison of protective clothing and gear, which is highly 
valuable for clothing industry to improve protective and comfort properties. However, they do not provide any information about the local or whole body human thermo-physiological response and the possible implications in different cases of use for the protective clothing.

Nowadays, mathematical models of human thermal physiology exist to predict the thermo-physiological state of the body (Fiala et al. 2001; 1999; Kobayashi and Tanabe 2013; Werner and Webb 1993). In general, such thermophysiological models include a simplified model for clothing including only a few static parameters, such as thermal and evaporative resistances and clothing area factor. Nevertheless, the dynamic nature of the thermal exchange occurring within the clothing might significantly affect the complex heat and mass transfer phenomena: moisture absorption-desorption cycles, condensation-evaporation cycles, or liquid moisture migration across clothing layers that can contribute to a substantial heat loss depending on fabric properties and moisture location (Fan and Cheng 2005a; Havenith et al. 2013; 2008; Wissler and Havenith 2009; Wu and Fan 2008). Clothing models describing such transient processes in the human skin-clothing-environment system have been introduced in the scientific literature; however, they have still some simplification in the modelling of decisive aspects, including air gaps and contact area between garments and the body surface (Fan and Cheng 2005b; Li et al. 2004; Lotens and Havenith 1994; Lotens et al. 1995). Additionally, they have scarcely been combined with advanced thermo-physiological models (Fiala et al. 1999; Tanabe et al. 2002; Wissler 1985) or, if combined, their performance has not been validated (Lotens 1993; Stolwijk 1971).

Thermal manikins enable experimental quantification of the real heat and mass exchange between the given actual gear and surrounding environment, even for complex transient conditions. Therefore, there is a reliable possibility of incorporating the exact heat loss of the skin into the thermo-physiological model calculations as an alternative to the virtual modelling of heat and mass transfer through the clothing. This could potentially lead to a more precise prediction of human thermal response (Jones 2002). Nevertheless, adding a thermo-physiological control to a thermal manikin implies different requirements for the manikin operation than those generally required by the manikin standards (ASTM F2370-10 2010; ISO15831 2004; ISO9920 2007). Human physiology usually presents heterogeneous temperature distributions on the skin surface. In addition, skin temperatures undergo frequent and fast changes while sweat secretion and evaporation occurs dynamically from the human skin. The manikins' limited ability to closely reproduce the skin temperature distribution and evaporation rates throughout the exposure in moderate and extreme scenarios might compromise the precision of the predictions.
Several attempts to couple thermal manikins (full-body manikins and cylinders) with thermo-physiological models have been successfully undertaken for the evaluation of clothing, transient automotive environments, ventilated seats, and cooling garments. The first of such a tool, reported in the literature, was developed for the automotive industry at the National Renewable Energy Laboratory (CO, USA) (Farrington et al. 2004; Rugh et al. 2004). In this study, they coupled the ADAM manikin with a thermo-physiological finite-element model and the Berkeley comfort model (Smith 1991; Zhang 2003). The manikin measured the heat loss from each body segment while the thermo-physiological finite-element model calculated the surface temperatures and sweat rates for each segment accordingly. This coupling principle has been successfully applied in other systems such as the single-sector thermo-physiological human simulator which represented the whole human body (Psikuta et al. 2008). The predominance of a coupled system was proven for static and dynamic heat and mass processes through clothing (Psikuta 2009; Psikuta et al. 2013b). Redortier and Voelcker (2010) also applied this principle for the coupling of Xu's sixsegment thermo-physiological model with a 38-zone Newton sweating manikin (Thermetrics, USA) (Xu and Werner 1997). A good agreement was observed with human experimental data for a transient environmental exposure; however, at the same time, some significant discrepancies in exercising scenarios occurred. Further efforts were suggested to increase the accuracy and adequacy of the sweating, such as incorporating diffusive sweating (Redortier and Voelcker 2011; 2010).

Up to now, coupled systems always included wholebody manikins (Curran et al. 2014; Farrington et al. 2005; Psikuta et al. 2008); however, the partial coupling of a body part manikin with a thermo-physiological model is yet to be addressed. The aim of this work was to develop a novel thermo-physiological human head simulator for headgear evaluation, based on the coupling of a thermal head manikin with a thermo-physiological model. In this coupled system, the heat flux at the head-site is directly measured by the manikin, whereas the rest of the body is virtually simulated. As a crucial initial step, the opportunities and limitations of the coupled parts need to be evaluated. Thus, the preliminary validation study of the thermophysiological model and the investigation of the thermal constraints of the head manikin are also presented. Moreover, a preliminary validation study based on a nude head and simple headgear cases is presented. The initial understanding of the heat and mass transfer exchanges on the head manikin surface is fundamental for interpreting the results in complex headgear scenarios. In such a case, the system can realistically reproduce the effect of clothing on the net heat exchange between the skin and the environment and its impact on the wearer's thermal response. 


\section{System development}

\section{System components}

The mathematical model of human thermo-physiology is the model developed by Fiala et al. (Fiala and Havenith 2015; Fiala et al. 2012; 2001, 1999) in its most recent version released in 2015 (FPCm5.3. model, Ergonsim, Germany). It consists of two interacting systems: the controlled, passive system and the controlling, active system. The passive system includes the physical characteristics of the human tissue and the heat and mass transfer occurring within and between the body elements, as well as between the body surface and the environment. The modelling of the sensible and latent heat exchanges between the body surface and the environment include the clothing locally represented by thermal and evaporative resistances, the clothing area factors, long-wave radiation surface emissivity, and short-wave radiation surface absorptivity. The body is divided into 20 multi-layered body elements (head, face, neck, thorax, abdomen, hip, shoulders, upper arms, lower arms, hands, upper legs, lower legs, and feet). In particular, the head element consists of a forehead and a cranial sector, the face has one anterior and two superior sectors, and neck consists of an anterior, posterior, and two superior sectors. The active system predicts the thermoregulatory actions driven by the central and peripheral nervous systems including vasomotion, shivering, and sweating.

A thermal nine-zone head manikin was selected to measure the local heat transfer (Sweating Thermal Head, Thermetrics,
USA, 2012). This manikin has been proven to provide relevant data about the local heat transfer through headgear systems (Martínez et al. 2016). The thermal head manikin's surface is divided into nine independent heated zones capable of measuring the individual heat losses and surface temperatures as well as the control of sweat rates. The cranial region of the nine-zone manikin was finely segmented into six independent zones typically covered by headgear. The zones included the right and left temples which incorporated serial fragmentation of the area in-between for a more detailed investigation of heat transfer from anterior to posterior parts. The face, forehead, and neck were the remaining independent zones. The sweating system of the head manikin consists of a general pump with each zone flow being controlled by micro-valves. The head manikin is equipped with a tight elastic fabric which has to be placed on the manikin to evenly distribute the sweat over the entire head surface (Martínez et al. 2015).

\section{Coupling method}

The coupling procedure was based on a real-time feedback loop for controlling the head manikin using the thermophysiological model. In each iteration, the thermophysiological model calculated local surface temperature and sweat rates in real-time, based on heat loss from the manikin surface measured for each part of the head (see Fig. 1). This coupling principle has already been successfully applied to a single-sector thermal simulator (Psikuta et al. 2008). However, in the case of the multi-sector thermo-physiological

Fig. 1 Coupling principle

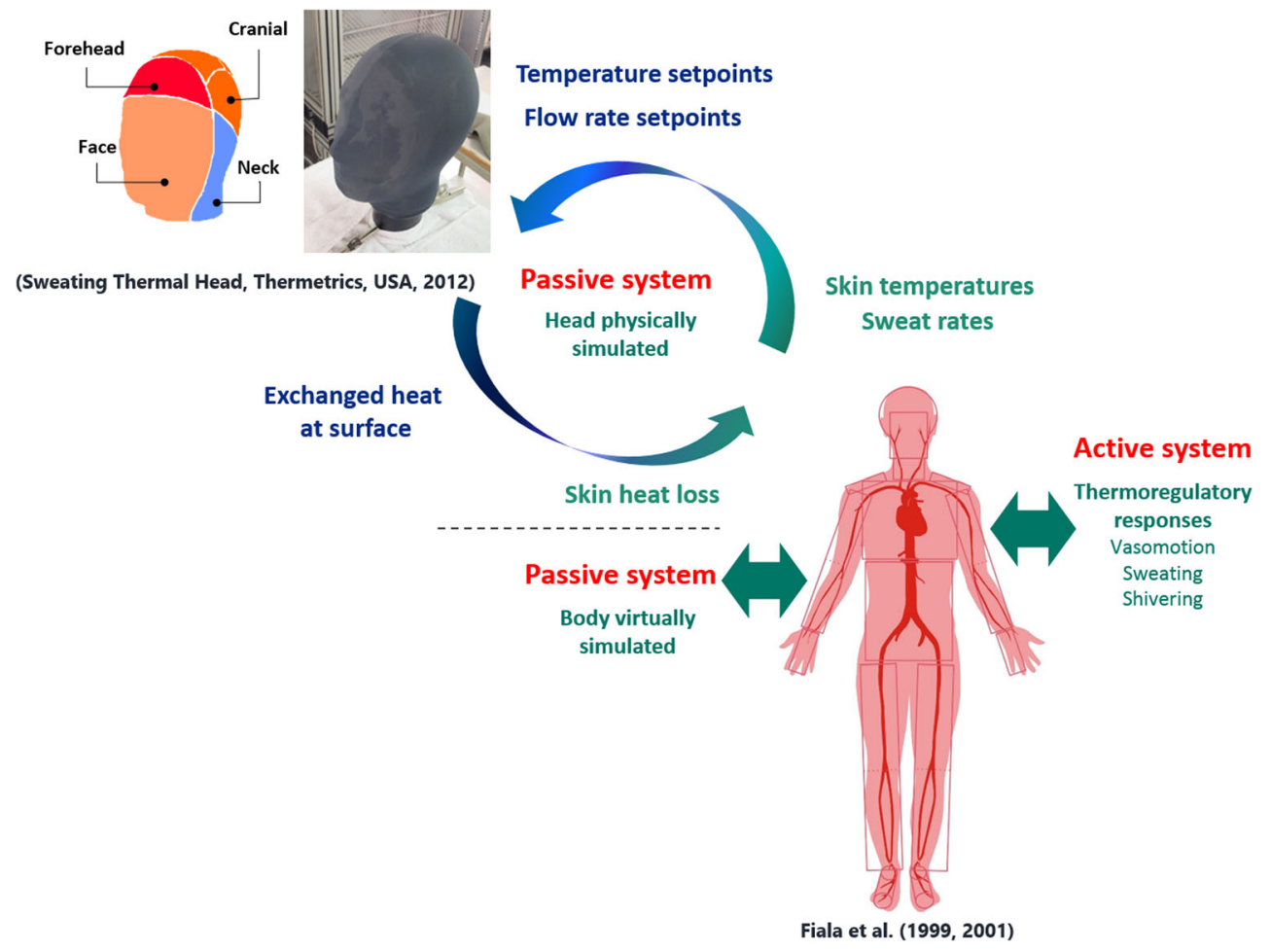


head simulator, the real local heat flux data is only available for the head. Therefore, the rest of the body needs to be simulated virtually. Accordingly, the model was challenged to simultaneously accept different types of boundary conditions, such as measured surface heat losses at the head-site (so-called in the FPCm5.3. software boundary condition 2, hereafter $\mathrm{BC} 2$ ) and virtual environmental conditions for the rest of the body (so-called in the FPCm5.3. software boundary condition 1, hereafter BC1). The thermo-physiological model was able to calculate the resulting local skin temperatures and sweat rates at the head-site based on the measured heat exchange. Therefore, the multi-sector thermo-physiological head simulator is required to accurately measure the heat flux exchanged with the environment at each head sector. This can then provide a reliable prediction of thermo-physiological response in both, transient and steady-state exposures.

\section{Requirements for individual components}

\section{Head segmentation according to human physiology}

Since the head manikin segmentation did not correspond to the segmentation of the thermo-physiological model, some sectors and zones in the model and head manikin were grouped to match similar body areas. The physiological control of the head manikin was then based on four independent head parts, including the forehead, the cranial part, the face, and the neck. This allocation, however, implied that the cranial and face parts were smaller in the head manikin by 10 and $6 \%$, respectively, in comparison to the thermo-physiological model. In contrast, the neck and forehead parts were bigger in the head manikin by 2 and $57 \%$, respectively, when compared to the model. The exact body division and attributed areas reflect the rather arbitrary decision of the model author, since the experimental data available for the model development is largely obtained for discrete number of points (e.g., temperature for entire back corresponds to a single spot measurement at the location of the temperature sensor). This means that the plausibility of such a small variation in surface area between the model and the manikin may have no influence, provided that the basic geometry and orientation of body segments remain similar.

\section{Head heat loss within a physiological range}

The head manikin provides a simplified geometry of the human head. Due to its materials and thicknesses, simplified features such as ears lack thermal interaction with a fullbody shape. As a result, the heat fluxes measured by the head manikin for a certain surface temperature could vary from the heat fluxes observed for the human skin at the same temperature. Therefore, the actual heat transfer coefficients of the head manikin have to be similar to those used by the thermo-physiological model for each head part, ensuring the same calculations are made.

The natural convective and radiative heat transfer coefficients used by the thermo-physiological model were compared for each head part, with those measured using the head manikin for a scenario to include a sedentary nude person in upright position exposed for $1 \mathrm{~h}$ at an ambience of $20^{\circ} \mathrm{C} / 50 \%$ $\mathrm{RH} / \mathrm{still}$ air $\left(v_{a}=0.1 \mathrm{~m} \mathrm{~s}^{-1}\right)$. The equivalent head manikin heat transfer coefficients were calculated based on the steady-state heating power needed to keep each head part surface temperature at $35{ }^{\circ} \mathrm{C}(30 \mathrm{~min}$ with heating power variation within $\pm 3 \%$ ). The heat transfer coefficient for each part of the head was calculated according to Eq. 1 .

$h_{\text {net }}=\frac{\mathrm{HF}_{\text {part }}}{T_{\text {part }}-T_{\text {air }}}$

where $\mathrm{HF}_{\text {part }}$ is the heat flux for each part of the head in $\mathrm{W} \mathrm{m}{ }^{-2}, T_{\text {part }}$ is the surface temperature at the corresponding head part, and $T_{\text {air }}$ is the actual air temperature in the climatic chamber, both in ${ }^{\circ} \mathrm{C}$.

The comparison resulted in higher net heat transfer coefficients for natural convection and radiation measured with the head manikin when compared to the calculated coefficients by the model. The coefficients of the head manikin were bigger by $1.5 \%$ for the forehead and cranial parts in comparison to the model, whereas for the face and neck, the discrepancies increased up to 10.7 and $17.2 \%$, respectively. The net heat transfer coefficients observed for a full-body manikin were closer to those in the thermo-physiological model (Psikuta et al. 2016). Hence, the heat transfer coefficients observed at head-site were certainly affected by the absence of the rest of the body, beneath the head (thermal plume). Therefore, some slight deviations occur between the heat flux measured by the head manikin and those of the human skin heat loss predicted by the thermo-physiological model, especially in high heat loss exposures at the face and neck parts.

\section{Heterogeneous surface temperature at head-site}

Heterogeneous temperature distribution over the head surface is often the case in the human physiology. Most thermal manikins are firstly conceived to operate at homogeneous surface temperatures, where temperature gradients between head parts could result in some uncontrolled lateral heat transfer by conduction or internal convection and radiation, resulting in subsequent inaccuracies in the measured heat fluxes. These inaccuracies in measured heat flux could affect the thermophysiological response predicted by the multi-sector human head simulator. Therefore, the lateral heat loss due to the temperature gradients between zones was quantified in two scenarios, representing a high heat loss scenario with extreme heterogeneous surface temperature (scenario 1 ) and a low heat 
loss scenario with moderate heterogeneous surface temperature (scenario 2).

The skin temperatures for each head part were simulated with the thermo-physiological model. Scenarios consisted of a nude person exercising for $2 \mathrm{~h}$ with moderate activity $(3 \mathrm{met}$, where met is the metabolic equivalent of task, 1 met $=58.2 \mathrm{~W} \mathrm{~m}^{2}$ ) in an ambient temperature of $35^{\circ} \mathrm{C}$ that suddenly moved into an environment at $5{ }^{\circ} \mathrm{C}$ (scenario 1 ) or $25{ }^{\circ} \mathrm{C}$ (scenario 2). The activity level remained constant over the 2-h exposure. The heterogeneous surface temperature distribution obtained at the end of the exposure was set at the head manikin parts for scenarios 1 and 2, respectively (see Table 1). Additionally, a series of homogeneous surface temperature distribution tests, corresponding to the temperature set points for the individual body parts in scenarios 1 and 2, were carried out. For both, heterogeneous and homogeneous surface temperature distribution tests, the steady-state heating power from each head part was measured (30 min with heating power variation within $\pm 3 \%$ ). For each head part, the heat flux measured for the heterogeneous and homogeneous temperature distribution at the corresponding set point was compared. Table 1 shows the relative difference expressed as a percentage of the corresponding homogeneous heat flux that was considered as the uncontrolled lateral heat exchange exclusively due to a heterogeneous temperature distribution. This was obtained for each of the four head parts foreseen in the coupled system. Table 1 includes the absolute heat flux values for a more comprehensive interpretation.

\section{Head thermal responsiveness}

The skin temperature of the human head changes dynamically as an adaptive thermo-physiological response to the environmental heat exchange. When coupled with the thermophysiological model, the thermal responsiveness of the head manikin could impair a close follow-up of the dynamic changes in the surface temperature, and effectively, mislead the course of the simulated thermo-physiological response. Thus, the head manikin had to react as fast as the human physiology does. The maximum heating, passive cooling, and controlled responsiveness were evaluated.

To determine the maximal changes in the head skin temperature for extreme transient conditions, a systematic batch of simulations were carried out for such conditions using the thermo-physiological model. First, to characterize the transient passive response of the head manikin, a heating test at the maximum nominal power $\left(800 \mathrm{~W} \mathrm{~m}^{-2}\right)$ and two cooling tests, in which the head manikin was left to cool from an initial $35{ }^{\circ} \mathrm{C}$ surface temperature, down to the ambient temperature of 5 and $25^{\circ} \mathrm{C}$, were carried out. Secondly, to characterize the manikin responsiveness when controlled by the default controller settings, a stepwise cycle consisting of step changes in surface temperature of $3,2,1$, and $0.5^{\circ} \mathrm{C}$ from a $35^{\circ} \mathrm{C}$ reference temperature. This would in turn represent moderate and extreme physiological 1-min transients, to then be carried out at 5 and $25^{\circ} \mathrm{C}$. The time needed to accomplish the temperature change of the required set point temperature with a tolerance of $0.2^{\circ} \mathrm{C}$ was determined.

The maximal temperature increase within $1 \mathrm{~min}$ at the skin of the human head was predicted by the thermo-physiological model to be $2.15^{\circ} \mathrm{C}$. This occurred when a nude person precooled at $10{ }^{\circ} \mathrm{C}$ with no activity (sedentary posture, activity level of $1 \mathrm{met}$ ) for $2 \mathrm{~h}$ and then was suddenly moved to an environment of $45^{\circ} \mathrm{C}$ air temperature, regardless the activity level. The maximum temperature increase observed in the head manikin was $6{ }^{\circ} \mathrm{C} \mathrm{min}{ }^{-1}$. However, when controlled by the controller default settings, the thermal head manikin needed on average $3.2 \mathrm{~min}$ to achieve an increase of $2{ }^{\circ} \mathrm{C}$ in surface temperature (Fig. 2b).

The maximum skin temperature decrease at the head, within $1 \mathrm{~min}$, was predicted by the thermo-physiological model to be $0.8^{\circ} \mathrm{C}$ for a thermoneutral person moving into an ambient of $5{ }^{\circ} \mathrm{C}$. For the head manikin, the maximal uncontrolled reduction in the surface temperature within $1 \mathrm{~min}$ was found to be $-1.9^{\circ} \mathrm{C} \mathrm{min}^{-1}$, when cooling from a surface temperature of 35 to $5{ }^{\circ} \mathrm{C}$ ambient temperature (Fig. 2a). However, when the cooling rate was modulated by the controller with default settings, it took $3.3 \mathrm{~min}$ on average to reduce surface temperature by $2{ }^{\circ} \mathrm{C}$ (Fig. 2 b).

As thermal manikins are mainly applied in standardized measurements including steady-state exposures, the parameters of the controller are optimized to prevent over- and undershooting in the surface temperatures and to maximize the power output stability. For dynamic measurement conditions, for example, in the case of a physiological simulation, the controller settings need to be adjusted if necessary, to provide the faster response required by the human physiology.

\section{Sweat evaporation efficiency and responsiveness}

Human sweat secretion usually corresponds to dynamic changes in environmental conditions and activity levels. According to the thermo-physiological model, the sweat evaporates from the human skin with an efficiency of $100 \%$, meaning that the evaporation of each gram of sweat removes equal heat to the latent heat of vaporization at the corresponding temperature. However, due to the characteristics of the head manikin sweating system, the water evaporates not directly from the head manikin surface, but from a tight-fitting fabric. Furthermore, the sweat secretion is limited to 21 sweating outlets; thus, evaporative efficiency might be reduced. This in turn means the predicted evaporative heat loss could be less than expected for a given amount of sweat according to the thermophysiological model predictions. Additionally, the evaporation responsiveness of the system could induce some delay between the onset of flow and the moment that the evaporative 
Table 1 Surface temperature set points and relative and absolute deviations in heat exchange (expressed in $\%$ and $\mathrm{W} \mathrm{m}^{-2}$, respectively) with regard to a theoretical uniform temperature distribution due to extreme and moderate non-uniform surface temperature distributions.
Positive values indicate parts providing higher heat flux in heterogeneous distribution than in homogeneous. Negative values represent the opposite. Heat flux has been compared between heterogeneous and homogeneous temperature distributions

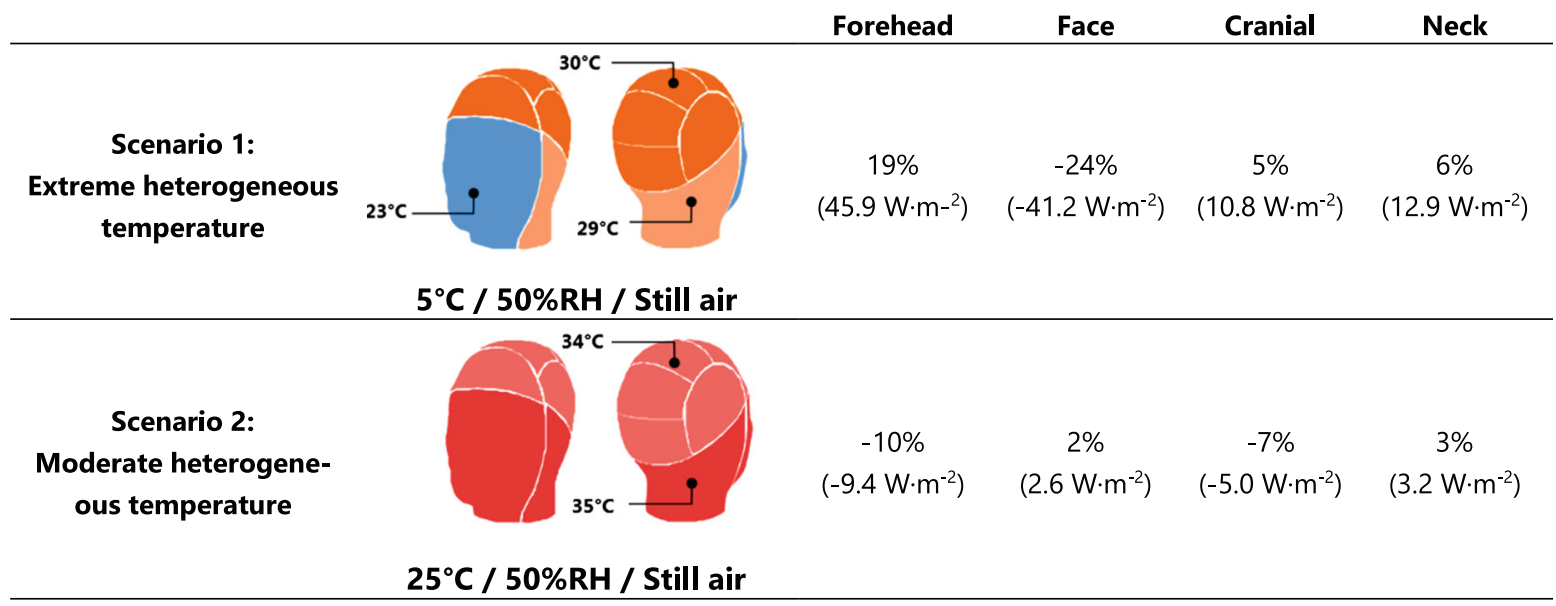

cooling becomes effective, as opposed to the immediate evaporation assumed in the thermo-physiological model. There fore, the evaporation efficiency and responsiveness had to be characterized, estimating to what extent they could affect the evaporative heat loss from the head manikin and how it compares to the human skin.

The evaporative efficiency of the tight-fitting fabric has been determined according to the experimental method reported by Burton (Burton 1944; Havenith et al. 2013) and calculated according to Eq. 2.

Eff $_{\text {evap }}=\frac{\text { Evaporative heat loss }}{\text { Mass loss } \lambda_{\mathrm{H} 2 \mathrm{O}}}$

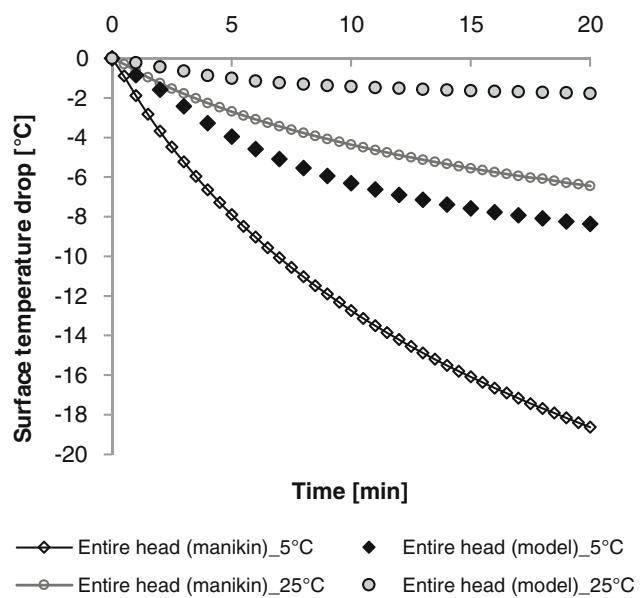

a)

Fig. 2 Thermal responsiveness of the head manikin. a Comparison of surface temperature drop measured on the head manikin and the skin temperature drop predicted by the thermo-physiological model at ambient temperature of 5 and $25^{\circ} \mathrm{C}$, respectively, for each defined head part. b Average time needed for the entire head to achieve the target temperature changes of $3,2,1$, and $0.5{ }^{\circ} \mathrm{C}$ positive and negative
Where the evaporative heat loss is the increase in heat loss in addition to the dry heat loss (i.e., total wet manikin heat loss - dry manikin heat loss) expressed in $\mathrm{W} \mathrm{m}^{-2}$, mass loss corresponds to the mass of the sweat liquid released on the manikin, expressed in $\mathrm{g}$, and $\lambda_{\mathrm{H} 20}$ is the latent heat of vaporization of water at $30^{\circ} \mathrm{C}$, expressed in $\mathrm{J} \mathrm{g}^{-1}$.

The evaporative efficiencies were measured for the different sweat rates at $25{ }^{\circ} \mathrm{C} / 50 \% /$ still air $\left(v_{a}<0.1 \mathrm{~m} \mathrm{~s}^{-1}\right)$. The entire head was controlled at a constant temperature of $35^{\circ} \mathrm{C}$ and a work cycle with different 1 -h phases of uniform sweating rates $\left(10,30,50,100,300,500\right.$, and $\left.1000 \mathrm{ml} \mathrm{m}^{-2} \mathrm{~h}^{-1}\right)$ was programmed. The phases with sweat rates were separated by drying phases to ensure that the measured heat flux at the

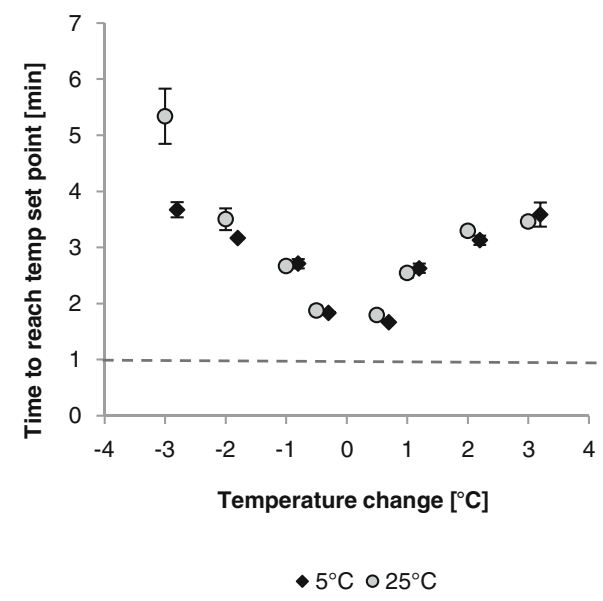

b)

calculated with $\pm 0.2{ }^{\circ} \mathrm{C}$ tolerance when the thermal reaction is modulated by the manikin controller at 5 and $25{ }^{\circ} \mathrm{C}$. The error bars show standard deviation of the four head parts foreseen in the coupled system. It should be noticed that time for a step change of $-3{ }^{\circ} \mathrm{C}$ in temperature ambient of $25^{\circ} \mathrm{C}$ is constrained by maximal passive cooling responsiveness of the head manikin 
beginning of each sweating phase was the same as in the initial dry phase $( \pm 3 \%)$. The average heat flux for a 15 min steady-state dry and sweating period was calculated for the entire head (average heat flux variation for all head zones below $5 \%$ ). Additional heat fluxes due to moisture evaporation at each sweat rate were obtained after subtracting the dry heat flux. In this work, the socalculated evaporative heat loss included not only strictly pure evaporative heat loss but also some marginal heat loss due to additional wet conduction of the skin fabric. Finally, a theoretical efficiency of the evaporation $\left(\right.$ Eff $\left._{\text {evap }}\right)$ at the head manikin surface was calculated by comparing the evaporative heat loss with the corresponding theoretical evaporative heat loss. This evaporative heat loss was calculated based on the mass loss if all secreted sweat was to evaporate, taking heat from the manikin surface at $30{ }^{\circ} \mathrm{C}\left(\lambda_{\mathrm{H} 2 \mathrm{O}}=2430 \mathrm{~J} \mathrm{~g} \mathrm{~g}^{-1}\right.$ at $30{ }^{\circ} \mathrm{C}$, (Havenith et al. 2013)). To calculate the evaporative heat loss, the steady-state evaporative heat loss was assumed to occur between the wetting and drying times. The wetting time for each sweating period was defined as the time elapsed from the sweat set point introduction to when the heat loss was increased up to $75 \%$ of the maximal steady-state evaporative heat loss, while drying time waited for a reduction of $75 \%$ after cessation of sweating. These percentages of the evaporative heat loss were chosen to generally approach the steady-state and allowing for any punctual variation of the system. To calculate the theoretical evaporative heat loss based on the mass loss, the evaporated mass is used to account for the sweat rate over the 1-h step. Although water drip-off for the entire head was found for 500 and $1000 \mathrm{ml} \mathrm{m}^{-2} \mathrm{~h}^{-1}$, the exact amount of water drip-off could not be precisely measured. On top of this, evaporative efficiency calculations for the entire head were not corrected by subtracting the water mass that dripped off. However, Koelblen (unpublished data) determined the maximum moisture content for this tight-fitting fabric and suggested negligible water drip-off for $500 \mathrm{ml} \mathrm{m}^{-2} \mathrm{~h}^{-1}$ but $1000 \mathrm{ml} \mathrm{m}^{-2} \mathrm{~h}^{-1}$ is evident for the entire head. The evaporation responsiveness to reach a certain evaporative cooling was analyzed based on the wetting time calculated for each sweating period according to the abovementioned definition.

In general, the evaporation efficiency tended to increase from $44 \%$ at $10 \mathrm{ml} \mathrm{m}^{-2} \mathrm{~h}^{-1}$ with the sweat rate till a maximum of 78 and $76 \%$, observed for the entire head at 300 and $500 \mathrm{ml} \mathrm{m}^{-2} \mathrm{~h}^{-1}$. It dramatically decreased for the highest sweat rate of $1000 \mathrm{ml} \mathrm{m}^{-2} \mathrm{~h}^{-1}$ as the calculation was not corrected for the water mass that dripped off. The average wetting times for the entire head varied between 3 and $10 \mathrm{~min}$ and tended to be slightly higher when sweat was set at 300 and $500 \mathrm{ml} \mathrm{m}^{-2} \mathrm{~h}^{-1}$. The lowest wetting times were observed for the minimum and maximum sweat rates, respectively.

\section{Using the heat loss as an integral feedback} from the environment

In a pure virtual simulation with the thermo-physiological model, the input boundary conditions are most usually described as a list of environmental parameters (further BC1) and when the thermo-physiological model is coupled with a thermal manikin, the boundary condition had to be introduced as the skin heat flux measured by the manikin (further $\mathrm{BC} 2$ ) for the coupled body parts and $\mathrm{BC} 1$ for the rest of the body. Applying $\mathrm{BC} 1$ or $\mathrm{BC} 2$ could lead to different thermo-physio logical predictions due to heat exchange and thermo-physio logical calculations being based on different information. The thermo-physiological model calculates the sweat rate based on the response of the central nervous system and the local correction factor, accounting for the hidromeiosis effect related to the skin wettedness. When applying $\mathrm{BC} 2$, the information on the skin wettedness was not available and consequently the predicted sweat rate was not reduced.

Two scenarios have been selected, such as cold-sedentary and warm-exercising exposure conditions (referred to as cold and warm hereafter), for quantifying the effect of excluding hidromeiosis when using different boundary conditions. The cold scenario represented a standard nude person resting $(0.8$ met) in an ambient of $15^{\circ} \mathrm{C} / 40 \% \mathrm{RH} / \mathrm{still} \mathrm{air}\left(V_{a}=0.06 \mathrm{~m} \mathrm{~s}^{-1}\right)$ for $2 \mathrm{~h}$. In the warm scenario, the same standard person was exercising (6 met) in an ambient $30{ }^{\circ} \mathrm{C} / 40 \% \mathrm{RH} / \mathrm{still}$ air $\left(V_{a}=0.1 \mathrm{~m} \mathrm{~s}^{-1}\right)$ for $2 \mathrm{~h}$. For each scenario, a simulation with $\mathrm{BC} 1$ was carried out. The local skin heat loss, obtained as an output for each body part from this simulation, was used as input for a simulation with $\mathrm{BC} 2$. Finally, a third simulation was done, combining the application of $\mathrm{BC} 2$ for head parts and $\mathrm{BC} 1$ for the rest of the body $(\mathrm{BC} 1 / \mathrm{BC} 2)$, as it is intended in the head manikin coupled with the model. The discrepancy between the predictions in the cases of $\mathrm{BC} 1, \mathrm{BC} 2$, and $\mathrm{BC} 1 /$ $\mathrm{BC} 2$, respectively, was statistically assessed by root-mean square deviation (rmsd) and by bias, similar to the study by Psikuta et al. (2013b).

The thermoregulation actions in the cold conditions, namely, regulation of skin blood flow and shivering, were predicted identically in all three cases, whereas in warm conditions, as expected, the total amount of secreted sweat that accumulated for $2 \mathrm{~h}$ at the end of the exposure was 274 and $51 \mathrm{~g}$ higher in case $\mathrm{BC} 2$ and $\mathrm{BC} 1 / \mathrm{BC} 2$ compared to case $\mathrm{BC} 1$, respectively. The cumulated sweat at forehead was 2.64 and $2.37 \mathrm{~g}$ higher for $\mathrm{BC} 2$ and $\mathrm{BC} 1 / \mathrm{BC} 2$, respectively, as compared to $\mathrm{BC} 1$. However, the resultant predicted overall and local body temperatures in warm conditions differed only slightly, i.e., the rmsd value was 0.05 and $0.17{ }^{\circ} \mathrm{C}$ for rectal and mean skin temperatures when comparing $\mathrm{BC} 2$ and $\mathrm{BC} 1$ cases, with both 
rmsd values staying at $0.01{ }^{\circ} \mathrm{C}$ when comparing $\mathrm{BC} 1 / \mathrm{BC} 2$ and $\mathrm{BC} 1$ cases, and for local skin temperatures at head-site, the rmsd was within 0.1 and $0.05{ }^{\circ} \mathrm{C}$ for head parts when comparing cases $\mathrm{BC} 2$ and $\mathrm{BC} 1 / \mathrm{BC} 2$ with $\mathrm{BC} 1$, respectively.

\section{Validation against human subject data}

Eight human exposures were selected to validate the predictions of the coupled system for a nude head and simple headgear cases (Table 2). These exposures represented combinations of cold, moderate, and warm environments, with and without activity. The study on the precision of the FPCm5.3 model alone for these exposures was provided elsewhere (Martínez et al. 2016). In the coupled simulations, the head manikin was dressed with the original clothing from experimental studies or clothing closely representing the one in use if necessary.

The precision and the accuracy of the coupled system predictions were statistically assessed by the rmsd and by the bias, similar to the study by Psikuta et al. (2013b). Rmsd is the average absolute difference between the results of simulations and the corresponding human experiments, whereas the bias quantifies the averaged error, i.e., literal difference between a prediction and a measurement, including its sign, and indicates any systematic deviation of the model. Both parameters were calculated for the core and mean skin temperatures and the local skin temperature at the forehead in each exposure, as the local temperature was available in most of the exposures. The fit of the coupled simulations were considered acceptable when the rmsd and bias were within the standard deviation of the experimental data (i.e., 0.2 and $1.0{ }^{\circ} \mathrm{C}$ for core and skin temperature (Psikuta et al. 2012)). Some exemplary results have been graphically presented and discussed in the discussion section to illustrate some of the main challenges faced by the coupled system.

Figure 3 shows the overall bias and rmsd values for the coupled simulations for the eight validation exposures. Over all core temperature rmsd and bias values were calculated for rectal temperature. Therefore, exposures 2,4 , and 5 were not included, as core temperature was measured at the intestinesite and a consistent bias ranging between 0.15 and $0.2^{\circ} \mathrm{C}$ has been reported in some studies (Casa et al. 2007; Easton et al. 2007; Teunissen et al. 2012). Bias and rmsd values for core and mean skin temperature stayed close to the average standard deviation observed in the experiments that was 0.26 \pm 0.04 and $0.61 \pm 0.14{ }^{\circ} \mathrm{C}$, respectively. The predictability of the forehead temperature in both systems was close to the average experimental standard deviation of $1.16 \pm 0.43{ }^{\circ} \mathrm{C}$ (average rmsd was $1.04 \pm 0.54{ }^{\circ} \mathrm{C}$ ). If clustering the exposures according to the activity level (Table 2 ), the average precision of coupled simulations was higher in the sedentary cluster with rmsd of $0.86 \pm 0.68{ }^{\circ} \mathrm{C}$ (exposures $1,3,6$, and 7 with activity $\leq 1$ met) than in the activity cluster with rmsd of $1.21 \pm 0.37{ }^{\circ} \mathrm{C}$ (exposures $2,4,5$, and 8 with activity $>1$ met) for the forehead temperature.

\section{Discussion}

This work presents the opportunities of a thermo-physio logical human head simulator to precisely represent the human thermal response when complex headgear is worn. First, the elements constituting of the coupled system have been evaluated separately.

The thermal head manikin was evaluated in the most demanding scenarios for the human thermo-physiology to determine the opportunities and limitations that could allow the coupled system to precisely mimic the human head thermal response. When heterogeneous surface temperature distribution was applied on the head manikin, the gradients between the head parts resulted in uncontrolled lateral heat exchange that could compromise the precision of skin temperature prediction at forehead and face. The passive heating and cooling responsiveness of the head manikin did not present any limitation for simulating sudden temperature step changes observed in the human response. However, when the manikin heating and cooling processes were modulated by the controller with default settings, the time needed to reach the temperature set point was longer than the time required by the human physiology. The average evaporation efficiency for the entire head studied at different sweat rates, ranged between 44 and $78 \%$ and no further increase was achieved with a higher sweat rate due to exceeding the maximum evaporation rate and a consequent water drip-off. Ideally, in a coupled simulation, the head manikin should closely represent the evaporation phenomena as it is in the human skin at head-site in the entire range of conditions, namely, similar sweat delivery responsiveness, similar evaporation rates in the same environment and similar capacity of holding water on its surface. Therefore, modifications of the sweat delivery system and water absorption properties of different tight-fitting fabrics could allow evaporation at the thermo-physiological human head simulator surface to approach the evaporation at the human skin surface, as previously suggested in the literature (Redortier and Voelcker 2011).

The evaluation of the thermo-physiological model revealed some inconsistencies between predictions calculated based on descriptive boundary conditions $\mathrm{BC} 1$ and $\mathrm{BC} 2$, despite considering the same total skin heat loss. In particular, the sweat secretion was overpredicted in the case of using $\mathrm{BC} 2$ because the information on the skin wettedness necessary to calculate the local sweat secretion inhibition was unavailable. The measurement of the total liquid water accumulation on the manikin surface, representing the skin wettedness, could be theoretically possible using the change of manikin weight as an 


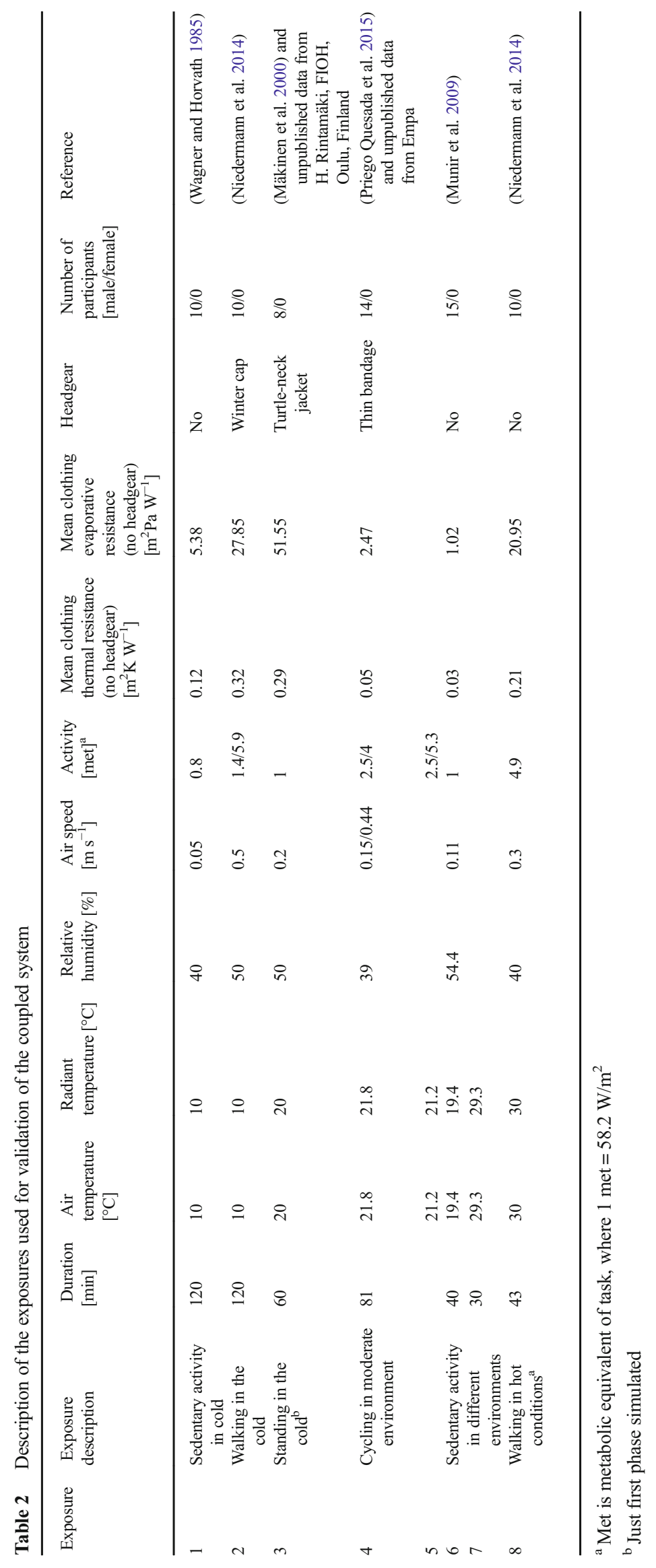


Fig. 3 Box-plot diagram of the overall bias and rmsd values calculated for the eight validation exposures. Box divisions correspond to data quartiles, upper whisker to the upper quartile plus 1.5 times the interquartile range, and lower whisker to the lower quartile minus 1.5 times the interquartile range
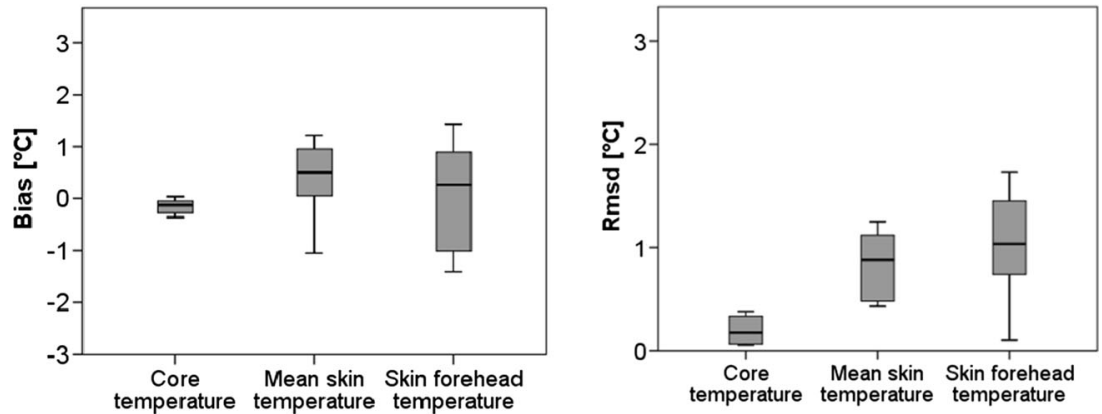

indicator. Nonetheless, such measurements would give only an overall value for all body parts and would not be possible as soon as any clothing or protective equipment was worn. In such a case, the location of the moisture accumulation would be not known and the correction for skin wettedness would be impossible. This limitation was observed when the thermophysiological model calculated local surface temperature and sweat rates in real time, when based on heat loss from the manikin surface measured for each head part. However, no information about this effect has been reported so far for coupled systems, where the thermal manikin surface temperatures are used as input parameters to the thermophysiological model and its correspondingly calculated metabolic heat flux in the human body and the skin heat loss at the manikin shell (Curran et al. 2014).

In general, the coupled system precisely predicted core temperature and mean skin temperature with average rmsd values staying close to the average standard deviation observed in the human experiments database, in agreement with accepted values in the literature of $0.2^{\circ} \mathrm{C}$ and below $1{ }^{\circ} \mathrm{C}$, respectively (Haslam and Parsons 1994; Psikuta et al. 2012). The coupled system precision for skin temperature at the forehead (average rmsd of $1.04 \pm 0.54{ }^{\circ} \mathrm{C}$ ) stayed within the average standard deviation observed in the experiments (see Fig. 3). This discrepancy was, however, more apparent for the exposures including activity than for the sedentary exposures.

In cold-sedentary exposures (exposure 1, Table 2), the coupled system underpredicted skin temperature at the forehead (Fig. 4a) and even lower than the pure virtual simulations. This could be due to slight uncontrolled lateral heat loss drifting from the forehead and cranial parts towards the face and neck parts, as their temperature was below the forehead and cranial skin temperatures by $3{ }^{\circ} \mathrm{C}$ on average along this cold exposure.

In activity exposures, the cooling of the skin had to be achieved mainly by the evaporation of the sweat. Figure $4 b$, c shows the prediction of forehead temperature and the corresponding sweat rate obtained in a moderate and a warm scenario, respectively (exposures 5 and 8, respectively, in Table 2). The temperature predicted by the coupled system was slightly above the temperature predicted by the pure virtual simulation in the first phase of sweating. The total amount of sweat secreted at the forehead was not very different in the moderate exposure 5 ( 0.89 and $0.83 \mathrm{~g}$ for the whole activity phase till minute 68 in the virtual and coupled simulation, respectively), but was however predicted higher by the coupled system than by the pure virtual simulation in the warm environment presented in exposure 8 ( 0.91 and $1.35 \mathrm{~g}$ for the whole activity phase till minute 43 in the virtual and coupled simulation, respectively). As shown in "Requirements for individual components" section, when the model applied BC2, the predicted sweat rates were higher than those predicted with $\mathrm{BC} 1$, due to the impossibility of accounting for the sweat suppression effect created by an increase in the skin wettedness. The combined effect of time delay and reduced evaporation efficiency observed in the head manikin for low sweat rates might have contributed to a limited evaporative cooling if compared with the pure virtual simulation ("Requirements for individual components" section).

Additionally, in the case of exposure 5 (Table 2), some temperature gradients of up to $1.8^{\circ} \mathrm{C}$ were observed between the forehead and face parts and could potentially produce some deviation in the measured heat loss due to uncontrolled lateral heat exchange and, consequently, in the local skin temperature. The coupled simulation showed a higher forehead temperature than the pure virtual simulation in both cases and had a better agreement with the human experimental data in exposure 8 . The opposite was observed in exposure 5 . The attachment method for the skin temperature sensors might have affected the temperature measurement differently for each experiment. Therefore, the interaction between the ambient conditions and the attachment method in each particular experiment could have generated differences in the heat and moisture transfer at the measurement-site (Buono and Ulrich 1998; Priego Quesada et al. 2015; Psikuta et al. 2013a).

Figure $4 d$ shows a skin temperature prediction at the forehead in the coupled simulations below the pure virtual simulation when exercising in the cold (exposure 2, Table 2). In this exposure, two participants were walking in a cold environment at $10{ }^{\circ} \mathrm{C}$ wearing a winter cap. In the pure virtual simulation, the thermal insulation value was measured first 
Fig. 4 Prediction of skin temperature (Tsk) and sweat rate (msw) at forehead for different exposures. a Exposure 1. Average person sitting in a cold environment at $\mathrm{Ta}=10^{\circ} \mathrm{C}$. $\mathbf{b}$ Exposure 5. Well-trained athletes cycling at 5.3 met in a moderate environment at $\mathrm{Ta}=21.2^{\circ} \mathrm{C}$. $\mathbf{c}$ Exposure 8. Well-trained athletes walking at 4.9 met in a warm environment at $\mathrm{Ta}=30^{\circ} \mathrm{C}$. $\mathbf{d}$ Exposure 2. Well-trained athletes walking at 5.9 met in a cold environment at $\mathrm{Ta}=10^{\circ} \mathrm{C}$

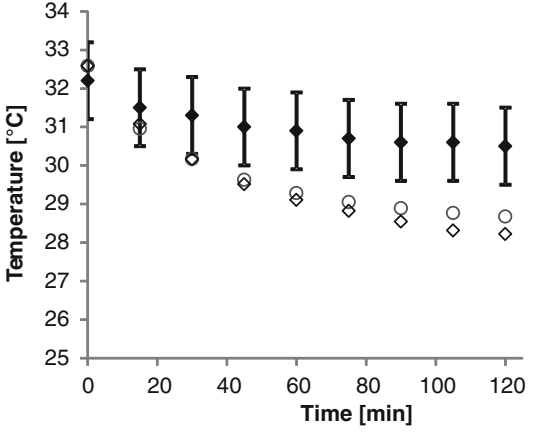

a)

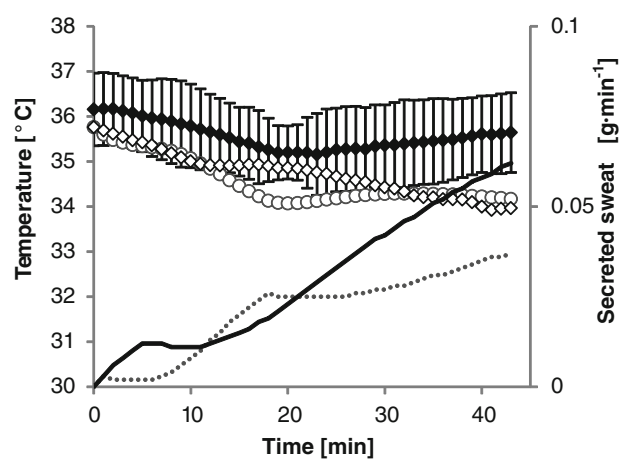

c)

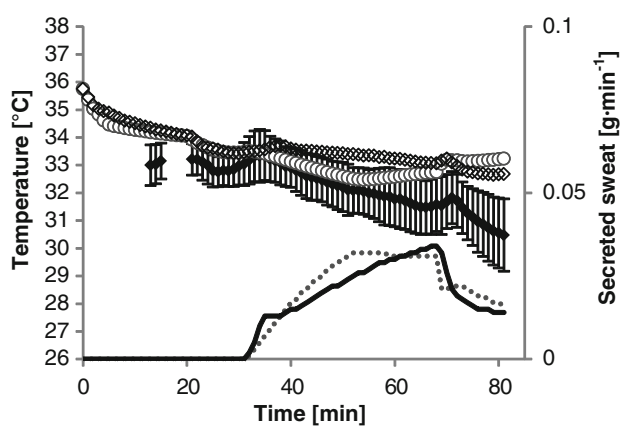

b)

- Tsk, experimental

....... msw, pure virtual sim — msw, coupled sim

- Tsk, pure virtual sim

.......m msw, pure virtual sim $\quad$ msw, coupled sim

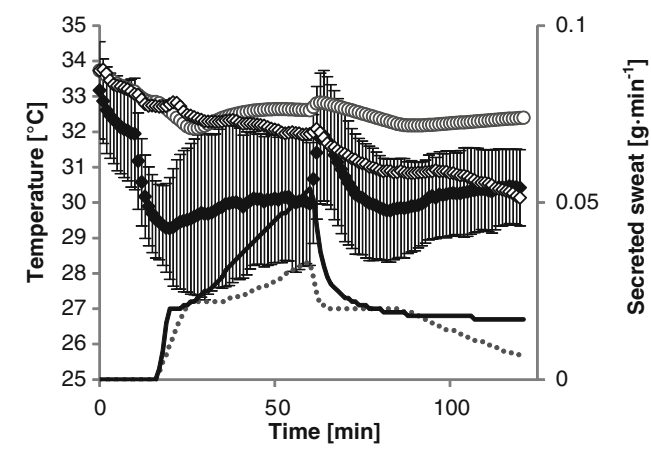

d) using the head manikin at a steady-state, and subsequently, the same winter cap was placed on the head manikin during the coupled simulation. In this case, skin temperature of the other head parts, either dressed or not, showed the common case observed for exposures involving the sweating function, in which the coupled simulation prediction for skin temperature was above the pure virtual simulation prediction. As the prediction of the skin temperature at the forehead in this exposure 2 showed exceptional behavior, it might be that this excess of sweat observed in the coupled simulation, although similar to the sweat excess in warm environment (exposure 8), was evaporating more efficiently in this cold environment than in warm conditions (1.01 and $1.47 \mathrm{~g}$ cumulated in the activity phase till minute 60 in the virtual and coupled simulation, respectively). However, in cold environments, other combined heat and moisture transfer phenomena such as increasing the net heat loss could occur within the winter cap in the coupled simulations that were not considered in the pure virtual simulation, due to the use of a simplified clothing model (i.e., reduction in skin fabric thermal resistance or condensation (Havenith et al. 2008)). The gap between both simulations and the experimental data could be related to the different ways of providing the skin temperature at the forehead. The coupled simulations provided the average skin temperature for the entire partially dressed forehead. However, in the human experiments, skin temperature at forehead was collected with a thermal contact sensor at one single point, which if allocated below the cap, would cause the measurement to correspond to the much colder skin temperature outside the winter cap.

In the cases of validation of selected exposures for cases representing participants wearing rather simple or no headgear, the thermo-physiological human head simulator predicted forehead temperature with similar precision to the model alone and within the experimental standard deviation, demonstrating its ability to represent the thermo-physiologically realistic heat and mass exchange at the skin head surface. The main advantage of the thermo-physiological human head simulator is that it can allow a precise quantification of the heat transfer occurring within the clothing, such as moisture absorptiondesorption cycles, condensation-evaporation cycles, or moisture migration across clothing layers. These complex thermal effects are commonly simplified in the pure virtual thermo-physiological simulations. Therefore, these results introduce the thermo-physiological human head simulator as a promising tool for a more precise prediction of the head thermal response. 


\section{Conclusions}

A novel thermo-physiological human head simulator for the testing of headgear was developed by coupling a thermal head manikin with a thermo-physiological model. This study demonstrated for the first time a coupling methodology for the body part manikin, in this case, head manikin, with the physiological model. Secondly, the crucial evaluation procedure for both components of this thermo-physiological head simulator was provided, including geometry and segmentation comparison, lateral heat exchange evaluation between segments, manikin thermal responsiveness, evaporation efficiency from the manikin surface, and the consequence of different forms of boundary condition used in the coupled system. The evaluation revealed reduced precision in the temperature predictions of the forehead and under extreme heterogeneous temperature distributions and no limitation for simulating temperature changes observed in the human physiology. The validation revealed precise predictions for core, mean skin, and forehead temperatures with average rmsd values within the average experimental standard deviation (rmsd of $0.20 \pm$ $0.15,0.83 \pm 0.34$, and $1.04 \pm 0.54{ }^{\circ} \mathrm{C}$, respectively).

The thermo-physiological head simulator allowed realistic wearing of the headgear placed on the head manikin and provided the exact quantification of the heat transfer phenomena occurring between the skin and the environment in any wearing case, including complex headgear and complex environments. The realistic information about the heat exchanged led to a more precise prediction of the human head thermo-physio logical response than the pure virtual simulations with solely a thermo-physiological model. The validation study showed the ability of the system to represent the human thermo-physio logical response and was essential for adequately interpreting the results in scenarios where more complex and dynamic heat exchange phenomena were present through clothing. The industry will benefit from this knowledge, leading to the development of helmet designs with enhanced thermal comfort and, therefore, achieving higher user acceptance.

Acknowledgments This work has been supported by the State Secretariat for Education, Research and Innovation (SBFI C11.0137) under the grant COST Action TU1101 project (http://www.bicyclehelmets.eu/) The authors gratefully acknowledge Dr. Matthew Morrissey and Rolf Stämpfli from Empa (St. Gallen, Switzerland) for their valuable contribution to programming of the coupling interface and Barbara Koelblen from Empa (St. Gallen, Switzerland) and Warsaw University of Technology (Warsaw, Poland) for providing the validation data and consultation.

\section{References}

ASTM F2370-10, 2010 (2010) Standard test method for measuring the evaporative resistance of clothing using a sweating manikin. ASTM International, West Conshohocken
Buono MJ, Ulrich RL (1998) Comparison of mean skin temperature using "covered" versus "uncovered" contact thermistors. Physiol Meas 19:297-300

Burton AC (1944) An analysis of the physiological effects of clothing in hot environments. National Research Council, Canada

Casa DJ, Becker SM, Ganio MS, Brown CM, Yeargin SW, Roti MW, Siegler J, Blowers JA, Glaviano NR, Huggins RA, Armstrong LE, Maresh CM (2007) Validity of devices that assess body temperature during outdoor exercise in the heat. J Athl Train 42:333-342

Curran AR, Peck SD, Hepokoski MA, Burke RA (2014) Physiological model control of a sweating thermal manikin. In: Ambience'14\&10i3m, Tampere, Finland, 7-9 Sept 2014, pp. 7-9

Easton C, Fudge BW, Pitsiladis YP (2007) Rectal, telemetry pill and tympanic membrane thermometry during exercise heat stress. J Therm Biol 32:78-86. doi:10.1016/j.jtherbio.2006.10.004

Fan J, Cheng X-J (2005a) Heat and moisture transfer with sorption and phase change through clothing assemblies: part I: experimental investigation. Text Res J 75:900-105. doi:10.1177/004051750507500301

Fan J, Cheng X-J (2005b) Heat and moisture transfer with sorption and phase change through clothing assemblies: part II: theoretical modeling, simulation, and comparison with experimental results. Text Res J 75:187-196. doi:10.1177/004051750507500301

Farrington RB, Rugh JP, Bharathan D, Burke R (2004) Use of a thermal manikin to evaluate human thermoregulatory responses in transient, non-uniform, thermal environments. In: Society of Automotive Engineers Technical Paper. pp. 2004-01-2345. SAE International. doi:10.4271/2004-01-2345

Farrington RB, Rugh JP, Bharathan D, Paul H, Bue G, Trevino L (2005). Using a sweating manikin, controlled by a human physiological model, to evaluate liquid cooling garments, in: Society of Automotive Engineers Technical Paper. doi:10.4271/2005-01-2971

Fiala D, Havenith G (2015) Modelling human heat transfer and temperature regulation, in: Springer-Verlag Berlin Heidelberg (Ed.), Studies in Mechanobiology, Tissue Engineering and Biomaterials. pp. 1-38. doi:10.1007/8415

Fiala D, Lomas KJ, Stohrer M (1999) A computer model of human thermoregulation for a wide range of environmental conditions: the passive system. J Appl Physiol 87:1957-1972

Fiala D, Lomas KJ, Stohrer M (2001) Computer prediction of human thermoregulatory and temperature responses to a wide range of environmental conditions. Int J Biometeorol 45:143-159. doi:10.1007 /s004840100099

Fiala D, Havenith G, Bröde P, Kampmann B, Jendritzky G (2012) UTCIFiala multi-node model of human heat transfer and temperature regulation. Int J Biometeorol 56:429-441. doi:10.1007/s00484011-0424-7

Haslam RA, Parsons KC (1994) Using computer-based models for predicting human thermal responses to hot and cold environments. Ergonomics 37:399-416. doi:10.1080/00140139408963659

Havenith G, Richards MG, Wang X, Bröde P, Candas V, Den Hartog E, Holmér I, Kuklane K, Meinander H, Nocker W (2008) Apparent latent heat of evaporation from clothing: attenuation and heat pipe effects. $\mathrm{J}$ Appl Physiol 104:142-149. doi:10.1152/japplphysiol.00612.2007

Havenith G, Bröde P, den Hartog E, Kuklane K, Holmer I, Rossi RM, Richards M, Farnworth B, Wang X (2013) Evaporative cooling: effective latent heat of evaporation in relation to evaporation distance from the skin. J Appl Physiol 114:778-785. doi:10.1152/japplphysiol.01271.2012

ISO15831 (2004) Clothing-physiological effects - measurement of thermal insulation by means of a thermal manikin. International Organisation for Standardisation, Geneva (Switzerland)

ISO9920 (2007) Ergonomics of the thermal environment - estimation of thermal insulation and water vapour resistance of a clothing ensemble. International Organisation for Standardisation, Geneva (Switzerland) 
Jones BW (2002) Capabilities and limitations of thermal models for use in thermal comfort standards. Energy Build 34:653-659. doi:10.1016 /S0378-7788(02)00016-6

Kobayashi Y, Tanabe S (2013) Development of JOS-2 human thermoregulation model with detailed vascular system. Build Environ 66: 1-10. doi:10.1016/j.buildenv.2013.04.013

Li Y, Li F, Liu Y, Luo Z (2004) An integrated model for simulating interactive thermal processes in human-clothing system. J Therm Biol 29:567-575. doi:10.1016/j.jtherbio.2004.08.071

Lotens WA (1993) Heat transfer from human wearing clothing. Techincal University Delft, Delft

Lotens WA, Havenith G (1994) Effects of moisture absorption in clothing on the human heat balance. Ergonomics 38:1092-1113

Lotens WA, van de Linde FJG, Havenith G (1995) Effect of condensation in clothing on heat transfer. Ergonomics 38:1114-1131

Mäkinen T, Gavhed D, Holmér I, Rintamäki H (2000) Thermal responses to cold wind of thermoneutral and cooled subjects. Eur J Appl Physiol 81: 397-402. doi:10.1007/s004210050060

Martínez N, Psikuta A, Rossi RM, Corberán JM, Annaheim S, (2016) Global and local heat transfer analysis for bicycle helmets using thermal head manikins. Int J Ind Ergon. 53:157-166. doi:10.1016 jj.ergon.2015.11.012

Martínez N, Psikuta A, Annaheim S, Corberán JM, Rossi RM (2015) Validation of a physiological model for controlling a thermal head simulator. 16th International Conference on Environmental Ergonomics, Portsmouth

Munir A, Takada S, Matsushita T (2009) Re-evaluation of Stolwijk's 25node human thermal model under thermal-transient conditions: prediction of skin temperature in low-activity conditions. Build Environ 44:1777-1787. doi:10.1016/j.buildenv.2008.11.016

Niedermann R, Wyss E, Annaheim S, Psikuta A, Davey S, Rossi RM (2014) Prediction of human core body temperature using noninvasive measurement methods. Int J Biometeorol 58:7-15. doi:10.1007/s00484-013-0687-2

Priego Quesada JI, Martínez Guillamón N, Cibrián Ortiz De Anda RM, Psikuta A, Annaheim S, Rossi RM, Corberán Salvador JM, Pérez Soriano P, Salvador Palmer R (2015) Effect of perspiration on skin temperature measurements by infrared thermography and contact thermometry during aerobic cycling. Infrared Phys Technol 72:6876. doi:10.1016/j.infrared.2015.07.008

Psikuta A (2009) Development of an "artificial human" for clothing research. De Monfort University, Leicester

Psikuta A, Richards M, Fiala D (2008) Single-sector thermophysiological human simulator. Physiol Meas 29:181-192

Psikuta A, Fiala D, Laschewski G, Jendritzky G, Richards M, Blazejczyk K, Mekjavič I, Rintamäki H, de Dear R, Havenith G (2012) Validation of the Fiala multi-node thermophysiological model for UTCI application. Int J Biometeorol 56:443-460

Psikuta A, Niedermann R, Rossi RM (2013a) Effect of ambient temperature and attachment method on surface temperature measurements. Int J Biometeorol. doi:10.1007/s00484-013-0669-4

Psikuta A, Wang L-C, Rossi RM (2013b) Prediction of the physiological response of humans wearing protective clothing using a thermophysiological human simulator. J Occup Environ Hyg 10: 222-232. doi:10.1080/15459624.2013.766562

Psikuta A, Kuklane K, Bogdan A, Havenith G, Annaheim S, Rossi RM (2016) Opportunities and constraints of presently used thermal manikins for thermophysiological simulation of the human body. Int $\mathbf{J}$ Biometeorol 60:435-446. doi:10.1007/s00484-015-1041-7

Redortier B, Voelcker T (2010) Implementation of thermo-physiological control on a multi-zone manikin. In: 8th International Meeting for Thermal Manikin and Modeling (8I3M), Victoria, Canada, 22-26 August 2010

Redortier B, Voelcker T (2011) A 38-zone thermal manikin with physiological control: validation for simulating thermal response of the body for sports exercise in cold and hot environment, in: 14th International Conference on Environmental Ergonomics. Napflio, Greece

Rugh JP, Farrington RB, Bharathan D, Vlahinos A, Burke R, Huizenga C, Zhang H (2004) Predicting human thermal comfort in a transient nonuniform thermal environment. Eur J Appl Physiol 92:721-727

Smith CE (1991) A transient three-dimensional model of the thermal system. MSc thesis, Kansas State University, Kansas

Stolwijk JA (1971) A mathematical model of physiological temperature regulation in man. NASA Contractor Report No. CR-1855, National Aeronautics and Space Administration, Washington, DC

Tanabe S, Kobayashi K, Nakano J, Ozeki Y (2002) Evaluation of thermal comfort using combined multi-node thermoregulation $(65 \mathrm{MN})$ and radiation models and computational fluid dynamics (CFD). Energy Build 34:637-646

Teunissen LPJ, de Haan A, de Koning JJ, Daanen HAM (2012) Telemetry pill versus rectal and esophageal temperature during extreme rates of exercise-induced core temperature change. Physiol Meas 33:915-924. doi:10.1088/0967-3334/33/6/915

Wagner JA, Horvath SM (1985) Influences of age and gender on human thermoregulatory responses to cold exposures. J Appl Physiol 58: $180-186$

Werner J, Webb P (1993) A six-cylinder model of human thermoregulation for general use on personal computers. Ann Physiol Anthropol 12:123-134. doi:10.2114/ahs1983.12.123

Wissler EH (1985) Mathematical simulation of human thermal behaviour using whole body models. In: Shitzer A, E.R.C. 1198 (eds) Heat transfer in medicine and biology — analysis and applications, vol 13. Plenum, New York, pp 325-373

Wissler EH, Havenith G (2009) A simple theoretical model of heat and moisture transport in multi-layer garments in cool ambient air. Eur J Appl Physiol 105:797-808. doi:10.1007/s00421-008-0966-5

Wu H, Fan J (2008) Study of heat and moisture transfer within multi-layer clothing assemblies consisting of different types of battings. Int $\mathrm{J}$ Therm Sci 47:641-647. doi:10.1016/j.ijthermalsci.2007.04.008

Xu X, Werner J (1997) A dynamic model of the human/clothing/environment-system. Appl Hum Sc 16:61-75

Zhang H (2003) Human thermal sensation and comfort in transient and nonuniform thermal environments. University of California, Berkeley 